\title{
Death and Digital Media
}

\section{Michael Arnold, Martin Gibbs, Tamara Kohn, James Meese, and Bjorn Nansen}

Afterword by Elizabeth Hallam

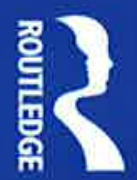


www.routiedge,com $\bullet$ an informa business 
First published 2018

2 bark Rquare,

and by Routledge
711 Third Avenue,

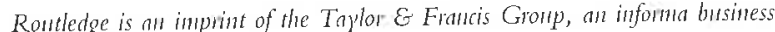

C 2018 min texr Miched Ady

and Bjorn Nansen; aftervord Elizabeth Hallam. The right of Michaci Amold, Martin Gibbs, Tamara Kolhn, James Mecse, and
Bjornn Nansen to be identified as authors of this work, and Flizabeth Hallam to identified as the author of the afterword, has been asserted by them in accorda
with sections 77 and 78 of the Copyright, Designs and Patents Act 1988 .

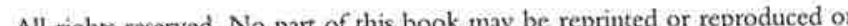
All rights reserved. No part of this book may be reprinted or reprodacd or
utilised in any form or by any electronic, mechanical, or other means, now known or hereafter invented, including photocopying and recording, or in any information storage or retrieval system, withour perminiden

(a) tradema
inffinge.

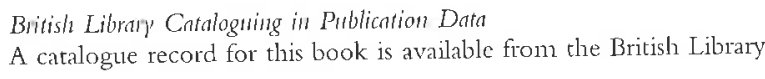

Librery of Congress Cartloging in Publication Data
A catalog record for this book has been requested

ISBN: 978-1-138-91795-8 (hibk)

ISBN: $798-1-1-138-91796-5$ (pbk)

ISBN: $978-1-315-688749$ (n)

Typeser in Bembo
by Taylor \& Francis Book
To all of us: The Future Dead 


\section{CONTENTS}

1 Death and digital media: an introduction

2 Pre-digital mediums, media, and mediations

3 The materialities of gravesites and websites

4 Death and social media: entanglements of policy and practice

5 Mixing repertoires: commemoration in digital games and online worlds

6 The funeral as a site of innovation

7 Looking to the future of life after death

Death and digital media: an afterword 


\section{DEATH AND DIGITAL MEDIA}

An introduction

News of a friend's unexpected death is received in a tweet; hearffelt messages are left on a recently deceased friend's Facebook page; an online memorial is created to allow people to share their stories and their grief; a collection of avatars hold an in-game service for a departed player in World of Warcraft; Facebook Live is used to stream the suicide of a teenager; selfies are taken at funerals; millions of strangers use social media to moum the death of a celebrity, some memorial websites attract no visitors, others 'go viral', many carry advertising; at sonte point in the futture the number of dead Facebook account holders will exceed the number who are living; social media memorial pages set up by family compete with prges set up by strangers; the dead remain saved to our contacts list, and are not deleted; a start-up company is hoping to replicate a dead person's personality by processing their digital data; a renote-controlled robot enables attendance at a funeral any'where on earth

Death and digital media have intersected over the last two decades in interesting, sometimes confronting, and usually complicated ways. While digital media are widely understood to be increasingly shaping our daily lives, people are now discovering that these media also affect our death, and in particular, how we are commemorated and remembered. This signifies something of a new terrain for death practices and for digital and social media practices, as the two come together to allow novel commemorative practices to both flourish and be contested.

Our book focuses on this important meeting point of death and digital media. We provide a detailed account of these new forms of digital commemoration across a variety of media, discuss how the funeral industry is reacting to these developments, and consider how these emergent practices fit into a broader social, cultural, and religious history of memorialisation and mourning. Taking this intercection as our point of deputure provides a unique perspective on many important secionts of humanity's contemporary situation. We are able consider the variety of ways people respond to death, how and why people use digital technologies at this ways people respond to death, his how this use shapes our experience. We consider 
how technological innovation participates in reimagining the deceased and reimagining relations between the living and the deceased.

Of course, it is not just death and digital media that are interacting in this space. Long-standing practices continue to shape our responses to death and inform the role digital media play in commemoration and memorialisation. Institutions of considerable standing and history continue to play their part. Religious institutions in particular are considering what role digital media might play in their policies and rituals. To this we might add the spiritual and metaphysical beliefs of people who might not be a part of an institutionalised religion, but expect to see a reflection of spirituality in all responses to death, including the digital. Secular institutions also overlay a framework of legislation and regulation that governs many aspects of a response to death, and businesses that provide the products and services associated with death are subject to this framework. In the developed world death is at the centre of a very large industry sector, and the commercial imperatives and motivations of funeral homes and digital application providers play an important part in the dynamics of our changing responses to death, in turn energising innovation and entrepreneurship in death products and services. And while this book's focus is an examination of digital technologies and practices of memorialisation and commemoration, we are mindful that this occurs against a backdrop of traditional practices, emotional responses, institutional positions, metaphysics and spirituality, legal and regulatory frameworks, and business and commercial interests, all of which contribute to these still comparatively nascent digital interventions in the experience of death.

\section{Digital technologies}

The proliferation of digital media across society in such a short and recent timeframe has been remarkable. The mobile phone, for example, has reached more people in a quicker time than any other technology in history, and its mobility, computational power, networked synchronicity, and user interfaces are embedding it in the daily life of billions. ${ }^{3}$ In a similar fashion, digital networks that were experiment curiosities fifty years ago are now indisnensable, have gone on to experimental ctrosis fustries from finance to tourism, and are used by billions of transform ? people ${ }^{2}$ on social media has atfected in with one another (see Bann, 2010). Sinilany, he honizen of ubiquitous computing xperience of social life.

Considering these developments, it is not surprising that entrepreneurs and innovators have attempted to transform the very conservative death industry, significant econonic sector, worth an estimated US\$16-20 bilion per annum in the United States, $A \cup$ ip 1 ilion per anin in Alstalla, and ${ }^{2}$ billon per antum in the UK, at the time of witing. These actors rightly identify the funeral industry as rich and
relatively unexplored teritory, but funeral directors and funeral homes are relatively resistant to new technologies, certainly in comparison to other service industries. In this context, much of the digital imnovation in this industry has not been at the instigation of funeral homes, but is occurring as a consequence of developments in other areas of digital media innovation and use, or through the interventions of ordinary people who have suffered bereavement, or who are preparing for their own death. Although the public at large does not use these terms, within the death industry the services and products offered are referred to as 'pre-need' (prior to a particular death), 'at-need' (at time of death), or 'post-need' (after the death), and in this introduction and the chapters that follow, we see how digital media act in all three stage-related categories.

To take one example, funeral companies are starting to seek expert advice on heir use of digital and social media, and will use social media 'pre-need' to build their profile in the market place. At the retail level, funeral companies are local businesses (though the ownership structure is often global), and this use of social buedia positions the funeral company as part and parcel of the local community and media positions the for whe will inevitably become potential customers. Dis the conscion accurrence or the bered will of a death, or as the services offered by funeral

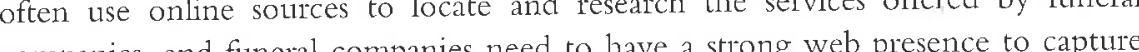
companies, and fir cor the funeral companie these customens. At he often use large flat-screens running caton-designed sofware applications to display

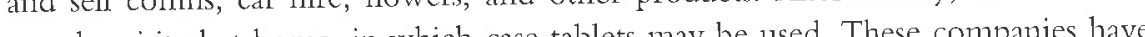
may be visited at home, in which case tables ma be unct decided that digital media are a better forn or product and scivice presentation than brochures or product display rooms. At the funeni, digial prodicts and services are also promment. Very commonly a relatively simple slideshow of projected images backed with nusic prepared by a firend or anly no bo to be four the service, but more sophisticated uses of digital media are also to be found. A professionally produced, high production-value biographical video may be shown, and retained in remembrance. Funerals are being live-streamed online to cater to increasingly dispersed groups of families and friends, and digital kiosks are being developed to allow mourners to ignore the condolence book and directly post to commemorative social media page from the funeral.

'Post-need', after the death and after the funeral, is a time of mourning and time for commemoration and memorialisation. Digital media are widely used following a death in ways that are sometimes a reflection of long-standing practices and are sometimes radical departures from what has gone before. In this context, is not uncommon for notifications of death to be received via social media, sometimes from the death bed, and sometimes months or years after the death. The use of websites to construct memorials to the dead is now commonplace and Facebook plays host to tens of millions of memorial sites for dead account holders. Virtua worlds and digital games like World of Warcraft also now play host to memorials and commemorative ceremonies, whilst several novel digital products, such 
memorial holograms and services that enable social media posts to be made in the name of the dead long after death, are emerging.

One way of understanding commemontion and memorialisation is as a set of Onc wactices that in different ways maintain social and material relations between the practices the person's life on behalf of those sill living and the headstone does not allow a

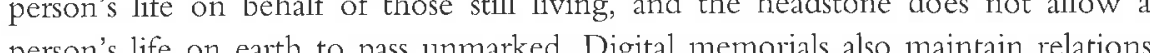
pesson's the on che hass

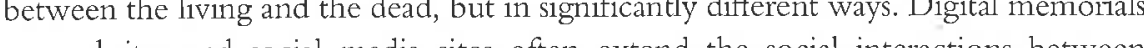

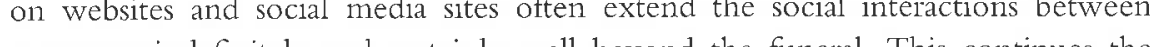

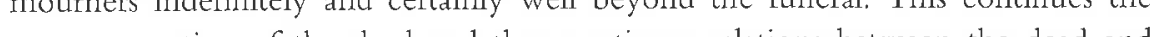

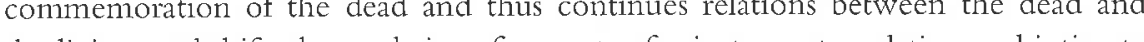
the living, and shitts these relations from acts of privarc contenplation and intimate expression to public declarations.

Larger publics are also invited to share in the commemoration of the dead. In the case of popular social media sites, commemorative participants and witnesses could potentially number millions of people. These new technologies change what previously might have been thought of as the separate domains of death as an intimate experience, and the public expression of death. While communing with the dead through a soliloquy delivered at the graveside implies a sense of intimacy, communing with the dead through a post to a publicly accessible website implies the interpolation of witnessing and the construction of a public. This moves grief from the private realm to the public sphere. These acts also collectively provide a context for a new form of posthumous biography to be created. This biography unfolds over time rather than being fixed in the eulogy, is authored by many people - intimates, friends and strangers alike - and animates a dynamic and ongoing relation between the living and the dead.

Through these digital media, the dead maintain a presence in the lives of the living. The dead often remain our Facebook friends, as contacts on our phone, or as search results in Google. The dead also persist on digital memorials. Mourners will converse with one another but also with the dead in a way that gives the dead an ongoing and active social life in the media-scape of the living. Our understanding of the relationship between biological death and social death is challenged by media that enable the living to animate the dead through online conversation or computational processes such as algorithms that directly animate the dead by automating the dead's social media posts.

As well as challenging the link between biological death and social death as necessary and concurrent, the application of some of these digital technologies also challenges our understanding of the sacred and the profane. Is it profane to send chotifiction of a death to intimates vin a Facebook strus undate? Is it necessary to comey the sad hews in peson, even though many of the decess's intimates may convey the sad din the to be daped wih a fooball scaf rater the attar to be draped wing a fooble cemetery and to spring up on highways and suburban streets all over the world; for pre-recorded videos of long-dead relatives to be viewed on occasions such as a great-great-granddaughter's twenty-first birthday; for funeral ceremonies to take place on beaches and in public parks and forests; for cremains ("cremated remains') to be turned into jewellery; for the body to be composted and used to fertilise plants; for crematoriums to capture residual heat from their furnaces to heat schools and swimming pools?

and swimming pools?
technologies are part and parcel of this move away from the institutionally mested and sometimes rigid protocols that have governed the funeral ceremony, the conduct of mourners and the final disposition of the body, towards what is often referred to as a 'more personalised' ceremony and form of body disposal. A often referted the individulity of the deceased rather

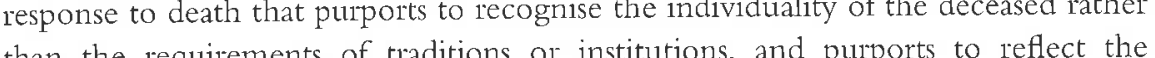
than the recures characteristics of the deceased's life and their values, is a response that is authentic to some, but pofnc to the who Wheres to deth hived Where the deceased led a life entwined with digital teethrologies one might expect scarf, rock-song and compost, this part is likely to be contested.

\section{Understanding digital commemoration}

From the mid-90s, as the internet became increasingly popular, scholars from a variety of disciplines have studied how the dead have been commemorated and remembered through digital media. Early studies focused on private commemorative pages that started to appear on the pre-web internet, as well as on bulletin boards, news groups and chat rooms, which were also used by the bereaved to gather around the deceased and seek mitual support (de Vies and Rutherford, 2004; Roberts, 2004; Roberts and Vidal, 2000; Veale, 2004). Carla Sofka, for example, noted that the interconnected nature of the web supported national and transnational mourning practices, like the creation of an internet sympathy card, 'for victims and survivors of the Oklahoma City bombing' (1997 560). However, the most prominent and notable finding amongst this early literature was that online memorials were not designed and used according to the traditions of formal obituaries, but were used by individuals to communicate either to a perceived audience of like-minded grievers, or directly to the deceased (de Vries and Rutherford, 2004). The sites also functioned as a 'returning' space, allowing a continual 'point of contact between the bereaved and the afterlife' (Socolovsky, 2004: 474). These studies identified new forms of memory and commemoration that were being created, and indeed, some of these practices are still in evidence today (see Marwick and Ellison, 2012).

The emergence of social networking in the early to mid-2000s only intensified these engagements as it provided a new communal space for intimacy between fiiends and family (Hutchings, 2012; Walter, Hourizi, Moncur, and Pitsillides, 
2011). This online intimacy did not stop once an individual had died, with scholars finting the the bereaved expressed felings of loss on numeweus socil networking finding that the bereaved expressed feelings of loss on numerous social networking (2012). 12). Myspace and Facebook pages were thred into a space for public mournin and, in a simila fashion to memoral webpages, the bereaved often returned to post

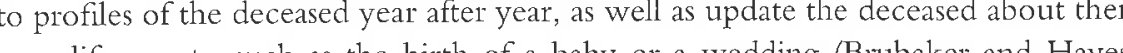
011). Peore 2011). Peeple wace lookn to the dea and, as Jed Babake and Janct Venesi note, the dead (were asstmed to still be active "in heaven" and contuing to anass experiences" (2010. 3). These memoria were also regularly accessed by stangers who noted through comments on pages 'that they either had also lost a firend, they did not know the deceased bit were saddened by the loss, or they distantly know the deceased' (DeGroot, 2014: 79). These studies reveal one of the most interesting things that have been found around these emergent practices of online memorialisation: the bereaved seek to maintain ties with the deac. While this phenomenon of establishing continuing bonds' is not new (Moss, 2004) (consider, for example, individuals who return to loved one's gravesite year after year), what is novel about these onthe memorial and social media profiles is the ease with which these bonds can seemingly be maintained, and the new forms of commenoration and engagement that emerg through this process. Social media profiles have also been shown to be tightly linked to the identity of the deceased, and thus the decision to remove a profile can be a particularly fraught act. Within this broader literature around death and digital media, a subset of scholars has specifically attended to the ontological issue around these active posthumous lives online, with many arguing that while numerous people are biologically dead they are very much socially alive and somewhat 'present' online (Kasket, 2012; Meese et al., 2015; Stokes, 2012).

The above body of work has provided important insights around the commemoration of the deceased online, outlining some of the common practices individuals are undertaking as well as the ongoing issues in the area. However, there has not yet been a comprehensive survey of how these interactions between death and digital media have progressed over time, or indeed an overarching study of how these emergent practices should be understood in relation to wider cultural and social changes around commemoration and memorialisation. This book is as an attempt to do so, providing the first substantial review of death and digital media. In addition to this, the monograph also details a range of newly emerging commemorative practices in digital games, through the application of data-mining an artificial intelligence, and on social media. Finally, the book offers an in-depth account of how the funeral industries in the US, the UK, and Austalia are cesponding to the challenges and opportunities digital media offer. With much of the extant literature around death and digital media ignoring these commercial

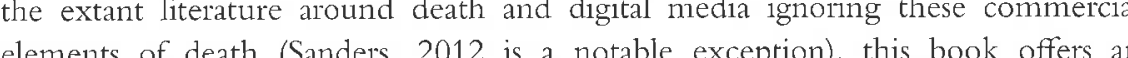

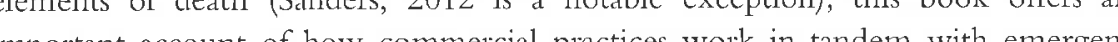
social practices to shape the commemorative digital landscape.
We position the aforementioned literature and our own research in relation to the wider body of work situated in death studies. In the next chapter, we discuss this field in more detail, but it is worth noting at the outset the broader trends emanating from this area. Scholars of death and commemoration have observed that there has been a shift away from mourning, witl commenoration increasingly functioning as a celebration of a life lived (Sanders, 2009), and religion now plays a diminishing (but not entirely absent) role in this process (Walter, 2011). The diminish tendency of public mourning (Brennan, 2008) and the production and growing tendency of public mourning (Bremanl, 2008) and the production and maintenance of vernacular mon

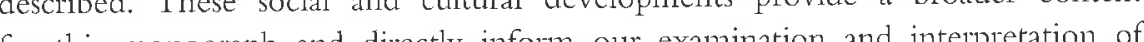
for this monograph and

\section{Key themes}

Several key themes have emerged as we have examined the relationship between death and digital media. Taken together these themes constitute what might be dhoughr of as the strands of interconnection that bring death and digital media together and enable them to lock into one another: the themes are personhood, relationality, materiality, and temporality.

Important among these are notions of just what it is to be a person, and the ways in which digital media are challenging and reshaping concepts of 'personhood'. To be a person is not a matter of unproblematic biological fact. Indeed, persons are social, cultural, and legal constructions rather than just biological entities. In many places and at many times not all humans have been accorded the status of persons, and not all persons are biological humans. For example, it is clear from the beginning of the etymology of the Latin persona that personhood did not refer to a singular, biological human being, delimited by the body. Roman law allowed some humans to possess multiple personas (citizen, landowner, father), whereas other humans (slaves, non-Romans) were not afforded the status of personhood at all. Intertwined with the ontological status of personhood is the agency of being afforded that status or denied that status. Persons have agency that non-persons do not have, and so in the United States, for example, the Supreme Court has afforded corporations the status of persons in regard to free speech, whereas prisoners, though biological humans, are not persons in this regard, and so may not, for example, have social media accounts. Important in the agency expressed by persons is the performance of social interaction. Persons have social standing, and may interact with other persons even in the absence of a living biological human. Anthropological research, for example, illustrates many instances of situations in which dead persons continue to interact meaningfully with living persons and continue to play a part in the lives of their living intimates and their community. In this context, where personhood and a living individual human are not isomorphic contexts, we discuss the implicarions of digtal media. As we explore, avatars are capable of materialising personas at a distance from an individul human and can act in digital worlds with humans 
and non-humans in ways that have significant social import. We describe numerous software aplications and digita envionments which were designed with the software applications and digital environments which were designed with the ant he of of the pos Tocial life of the peson cond in some cases, wa solit the techo living and the dead in ways that ahn to become increasingly indistinguishable, and at particular points even inconsequential - although, as we explore, these ambitions are often unrealised, or only partially so, and in a number of ways are not unproblematic. If the persona of the dead can still act int the world through the same forms of technical mediation that maintain the social life of the living, how can that entity be thought of within frames and understandings of 'person'?

A second theme important to our analysis is the relationality of responses to death, technologies, persons, publics, cultures, laws, social practices and norms, and all of the other actors that come together around death and digital media. None of these actors are privileged as driving change, or essentialised in a way that deternines their effect, but rather, change and effect emerge in response to the interactions of all actors. So we do not argue that digital media by its nature shapes the experience of death in any particular way, or that changed social norms are driving technological innovation. Teasing out the intricate threads that connect the actors in a mutually shaping relationship offers a more interesting and productive approach than attempting to arrange them in a hierarchy of cause and effect. An example of this approach is the use of the 'affordances' concept - a term perhaps not familiar to some readers. In brief, the affordances of a given technology refer to the manner in which the technology acts, contingent upon context. A mobile phone, for example, may act as a baby monitor, depending upon where it is placed, if a baby is present, if the phone-plan enables unlimited connection, if the phone battery will last through the night, and so on. This affordance is relational to all of these things, and is not the same as the decontextualised technical functions of the phone, such as the ability to send text, capture images, send and receive the spoken word, and so on. A closely related concept is the notion of 'mediation'. Mediation is a concept developed in science and technology studies and is used in this book to signify a form of relation in which the mediator reshapes those entities with which it is in relation, while at the same time reshaping itself. So, in examples to follow throughout the book, technologies such as newrspapers, television, smatrphone

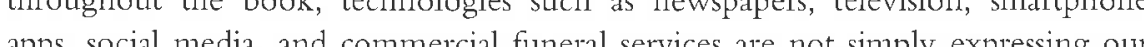
apps, social of exping actively shing what these technolos are, what they do, and what they meen to ats

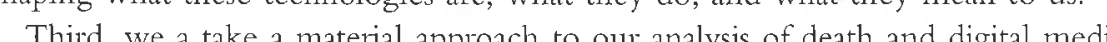

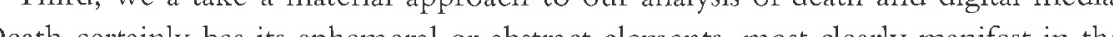
Death cer wh the

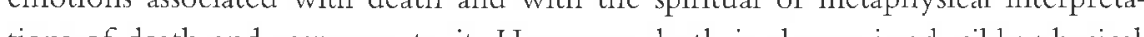

material phenomena, involving a dead body; the final disposition and decomposiion: and among the living, material memorials, legacy attefacts, embodied commemorations, and face to face encounters. The materiality of death and the important inmateriality of death come together in commemorations such as the committal, and in memorials such as one sees by the roadside, or on a website. Digital media of all kinds are similarly constituted of immaterial elements - symbols, Demiotics, iconography, aesthetics, and meaning, for example, all taking form throse media are

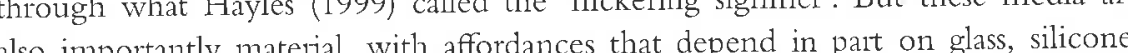
also importantly materal, wh and a whe with meaning

The final element that joins personhood, relationality, and materiality in our (in our analysis, is the temporal clement. Tent stancing of death and our resposes to it and in the

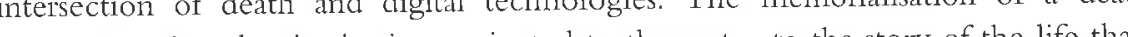

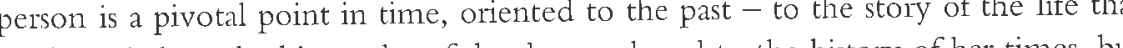
has been led, to the biography of the deccased, and to the history of of thes, but it is simultaneously an orientation to the futtre - to the legacy of the deceased, the mark made in the lives of those still ling, and to a frtwe in the abrence of the deceased. Digital media participate in this pivotal role, looking backwards and looking forwards, but do so in a way that in some respects differs from their nondigital alternatives. Social media memorials, for example, are temporally oriented to a multi-authored cascading presentism in which a biography may unfold over years, and is in a sense never complete. Mourning is also extended in a publicly declared way, and is similarly unfinished. To the extent that digital media afford constant present, the death and its memorialisation becomes something other than a pivotal point gesturing to a past and to a future.

\section{Mapping the field}

Responses to death across the globe are spectacularly diverse. Body disposal techniques include fermentation, sky-burials, composting, burning, and embalming. Funerary practices range from no ceremony at all through to large-scale, monthlong public festivals. Bereavement practices are diverse and include the use of professional mourners, the wearing of special clothes, and the foregoing of particular foods. The use of digital technologies is also diverse, and many factors such as differences in lifestyles, differences in commonly used applications, availability of infrastructure, technology marketing and pricing, social motivations for communication and so forth, create different socio-technical landscapes across the globe. To deal with even a cross-section of global death practices and digital technologies would be an encyclopaedic project, and so this book responds to this diversity by focusing on the particular cultural and teclnical milieus observed in the United Kingdom, Australin, and the United States. These milieus are very familiar to us, 
will be very familiar to many of our readers, have been available to us for extensive empirical research, are the source of most of the digital applications we discoss, and are the primary markets for most of the death related digital technologies we examine. Death itself is also experienced in diverse ways and a key factor in responses to death, digital or not, is the nature of the death itself. That is, a 'good death' occuring as a consequence of natural couses at an appropriate time a good death' age - is quite different to a viount death a young death, the deathe death that is unerpected, or that occurs as a consecuence of cin of a celebrity, a deatter forms of dea latelic response, and sometimes a poil iesponse, a public lepre 'go much more toly 'go '

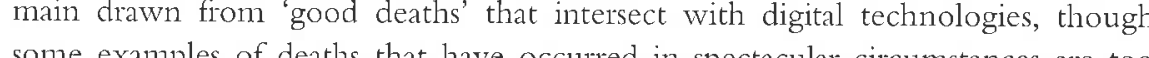
some examples of deats that have occurred in spectacular circumstances are too proming examples of death and digtal technologies, and though some reacers may well argue that some digital dmovations are bizare, we have been more interested in tracking what is emerging as accepted practice, or may plausibly be argued to become
accepted practice in the medium to long term.

\section{An interdisciplinary approach}

There is often confusion about approaches to research and scholarship that are identified as disciplinary, multidisciplinary, transdisciplinary, or interdisciplinary, and as this book is avowedly interdisciplinary, a word of explanation is warranted. Disciplinary approaches benefit from the evolution of research and scholarship that has taken place over many hundreds of years, an evolution that has been marked by ever increasing specialisation of fields of inquiry, methods, and tecliniques. So, for example, what was once 'Natural Philosophy', a field of inquiry that included all of nature and the universe, and used a common collection of broadly applicable methods such as empirical observation and induction, formal logic and deduction across this entire field, has now bifurcated into dozens and dozens of disciplines (chemistry, physics, biology, cosmology, geology, and so forth), which have in turn bifurcated into still more specialised disciplines such as organic chemistry, solid-state chemistry, industrial chemistry and so on, each with their own particular fields of inquiry, their own particular methods, and their own specialised techniques. In the context of this book, a disciplinary approach might have used the fields, methods, and techniques developed specifically in cultural or material anthropology, or media studies, or science and technology studies, or studies of human computer interaction. An anthropological approach might focus closely on sense-making among those with experience in death and digital media and might use techniques such as extensive periods of participant observation. A media studies approach might focus closely on the format or semiotics of the media content of mpemoach sites, using techniques such as content or discourse amalysis. A book u. derived from science and technology studies might be particularly concerned with the networks of technologies and people that come together through death and digital media, and might use conceptual tools aimed at analysing the symmetrical. manner in which the technologies shape the experience of death, and the way in which experience of death shapes the technologies. On the other hand, if the book was firmly positioned in the human computer interaction discipline, the focus might be on the design and the performance of the software applications associated with death, using methods to explore say, the scenarios of use envisaged by the designers, and the user experience of the technologies. Each of these approaches may well have produced valuable findings and a useful book, particularly for those working within the relevant scholarly field, but such a focused approach is not what informs the present volume.

An alternative is to approach death and digital media from a multidisciplinary perspective. A straight-forward way of achieving this would be to select one or perspective. A stes of death and digital media, then devote each chapter of the book to meres each nking a particular disciplinary perspective, and un analysis of the examples, each taking a pathers there is certainly value in The an examination of a given phenomenon from

again, that is not the approach we lave apted. This approach does draw upon Instead, we take an in

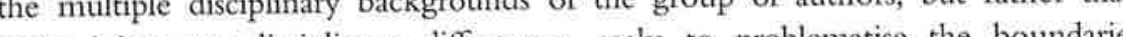

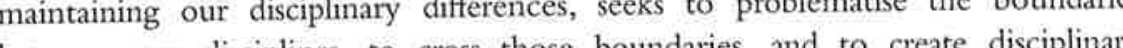

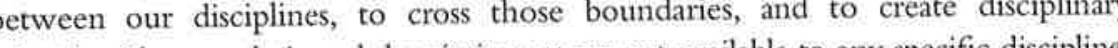

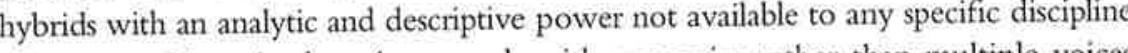
The overarching aim here is to speak with one voice ther than the voices, where that one voice has synthesised the muttally shaping interplay of ou respective background disciplines. Anthropology, science and teclnnology studies, media studies and human computer interaction thus shed their purty as each of us incorporates different fields of inquiry, different methods, and different techniques. Accordingly, fieldwork has been conducted at multiple sites that would probably not be brought together were it not for the interdisciplinary approach. Launching from media studies we examine the content and publics of online platforms an memorial sites, but to do so, draw on the ethnographic techniques most closely associated with anthropology. Anthrop ological anchects steh as headstones or sofware applications are taken seriously but, influenced by science and technology studies, are not only taken to be inert indicators of human sensibilities, but are also taken to be actors that, whilst not human, express agency in their own right. Human computer interaction allows us to look carefully at the interfaces and modes of participation invoked by software applications, but also to look closely at the myriad of actors that shape the experience beyond the user and the application And so, drawing from each discipline, some of our fieldwork has been conducted at funeral industry trade shows held annually between 2014-2016 in the United States, the United Kingdom, and Australia. At these trade shows we use method derived from science and technology studies and human-computer interaction studies, such as semi-structured interviews with identified key informants and focus 
group forums. But we also adopt methods more closely associated with anthropology, and we simply 'hung around' with funeral directors, with entrepreneurs that have developed applications and products, with the staff that work the cremator at crematoriums, and with funeral celebrants, casually observing their daily routines and engaging in informal conversation. Our fieldwork has also been conducted in online memorial sites, at in-game memorials and commemorations, and has used computational data collection methods related to commemoration practices within mobile social media applications. Here, hybridising fieldwork and modes of analysis from all disciplines, we in part perform a content analysis of the rext imagery, and functionality of the sites, and we examine the user interface and we expolote to the affordances of the technology, and we link these examples of technologies to other technologies and other medin and we interogate the metaphysical to spiritual underpinnings of the technotoges, and we trace the ites bick and historical memorial antecedents, and we map the web of retions back through people using the site and between the people and the technologies, all of which provides for a rich and mixed evidence-base.

Important to achieving the hybridity of interdisciplinarity while at the same time presenting a coherent account in a single voice, has been the simple process of the manuscript. We conduct fieldwork, which have argued long and hard about which sites to visit to gical principles to we to istemological principles to use to interpret that evidence, which examples to use to illustrate the ind which interpretations, and which wors to use from which discourses to express our account and our conclusions. The purposc of this argument has not been to reach a consensus through compronise, but to persuade one another of the valte of the position each of us begins from, and in the process, shifting that position from its disciplinary origins. To put it more simply, achieving interdisciplinarity is not limited to shaping and reshaping the words that go on the page, but extends to shaping and reshaping the application of our own disciplines and our understanding of other disciplines.

\section{Overview of chapters}

Our book examines a range of contemporary and historical sites, which allows us to capture the different ways that death and digital media are interacting today but also to place these interactions in a meaningful historical and cultural context. In similar fashion, our key themes of personhood, materiality, temporality, and relationality have not just emerged out of our current research but are also being developed in reference to the emerging body of scholarship focused on online commemoration, and the extensive scholarly studies of death and commention more generally. Therefore, in the chapters that follow, we report on our findings about how death and the digital are constituted on social media, websites, in online games, and in the funeral industry proper, but we also offer a detaled criticit overview of the cutrent state of scholarship in this area.
We begin with Chapter Two, which uses the phenomena of nineteenth century spirit mediums to introduce the history of a relationship between death and media and then goes on to analyse the mediation of death more broadly through attending to the development of a specialised 'death industry'. We contextualise the recent popular narratives around the awkward interactions between death and social media by showing how new technologies have always carried spiritual resonances, using a variery of examples, from the telegraph to funeral phonography to make our case. This overview also provides a contemporaneous socio-cultural history of commemoration view also provides a contemporaneous socio-cultural history of conmemoration
through which we explore the shift from institutional to vernacular methods of through which we explore the shift from institutional to vernacular methods of growth of the funeral industry, and the phenomenon of public mourning

We first engre with digital media in Chapter Three, where we examine the We first engage with digital media in Chapter Ihree, where we examine the emergence of online commenoration. This chapter analyss how people used the World Wide Web fom dead, and draws out the features of these websites by conpang wobsies with gravestones and headstones. Through this compas by

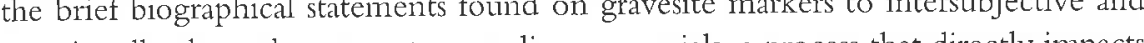
emotionally charged statents on the persontrod of the dead. We also see how he materality of hiese different technologies (from stone to computing) directly shapes the conmentative possibilities avalable to the bereaved and indeed changes the scope of ho porential commemorative act. This chapter begins the process of exploning the public nature of online commemoration and examines how a global audience interacted with these commemorative sites. However, this chapter also attends to the continuities between these two technological artefacts and so we also show how people were repurposing funerary traditions and rituals very eally on in the life of the web. Chapter Four continues and extends these conversations by examining one of the most notable issues surrounding the topic of digital media and death: the interactions between social media, the deceased, and the bereaved. This chapter begins by exploring the phenomenon of people dying public and networked deaths using case studies of two deaths that were deeply intertwined with socia media platforms: the death of Anna Svidersky who was famously memorialised on Myspace, and the death of Aziz Sergeyevich Shavershian, who was conmemorated on a variety of social media platforms. Through these studies we see how these networked forms of commemoration raise important questions about how the memory and legacy of the deceased is established and indeed 'policed' following death, which in turn hinges on important issues about an 'authentic' biography and the construction of the digital identity of the dead. This leads us to a discussion of concerns that have emerged in this area, such as the phenomenon of RIP trolling (where a public commemorative space is defaced); how social media platforms, and in particular Facebook, manage the digital legacies of the deceased; and how social and mobile media is incorporated into formal ritualised spaces like funerals.

In Chapter Five we focus on digital games and virtual worlds and show that this profitable and popular cultural industry has played an important role in extending 
commemoration practices through digital media. The chapter outlines a significant practices that have been undertaken in these spaces: fans of particular video games are commemorated in the game as a new character, players of online games create their own memorials for the departed, and many even hold services for deceased players in the game world. Once again we see reinterpretation of familiar funeral traditions as well as clear evidence of player forming communities and engaging in the sort of ritualistic behaviours around death that define a community. However, interestingly these behaviours also present a real challenge to existing routines and habits in games and can subvert even derail existing understandings of how a game should operate. How, for example, should players react in an online game oremised wound vioustor between clans, when a funeral service occurs mid-game? Chapter Six examines the funere industros an Con different ways, drawing on ferences in the US, Australia, and the UK. We see how funeral industry confinding it hard to enter a conservative market where fimenl diap companies are significal hare significant antornt of power when it comes to selecting what services are offered to customers. However, customers are also driving innovative practices by asking for memorative pretices. The ning - pre-n theral planmes

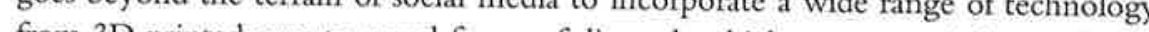
from 3D printed urns to novel forms of disposal, which numerous industry players see as being the key future site of innovation.

finally, Chapter Seven looks ahead to the future via emerging technologies that are pushing the boundaries of commenoration. We consider stat-up companies that aim to produce a life-like avatar of deceased ficnds and family members, the use of augmented reality to overlay information on gravestones, in-coffin sound systems that can be updated through Spotify, and companies that aim to facilitate sending messages from beyond the gave. These examples tell a compelling story of innovation around death and digital media, but also more aptly, about what innovators think commemoration does (or should do). Each invention tells us something interesting about what could be kept or remembered, and in many cases raises interesting ethical questions around what should be kept and the level of interaction we want to maintain with the dead. These innovations are not just simply narratives of technological advancement but also significant interventions in our existing understandings of our key themes: personhood, materiality, temporality, and relationality. We will see how these analytical themes are woven through all the chapters in this book. They will help us understand how the past informs present ideas about what it is to die and how relations are managed around death through a range of ever-changing media and materials. We will arrive at a future facing point where such changes - from simple elaborations on current practices to fanciful and quite radical physical and digital innovations around death - keep us ever hopeful and oriented towards new possibilities, new immortalities, new ways of being remembered.

\section{Notes}

1 blog.cartesian.com/the-1ise-of-mobile-phones-20-years-of-global-adoption 2 www.Internetlivestats.com/internet-users/ 
DEATH AND DIGITAL MEDIA

Death and Digital Media provides a critical overview of how people mourn, commemorate, and interact with the dead through digital media. It maps the hiscommemorate, and interact with the dead through digital media. It maps the his-
torical and shifting landscape of digital death, considering a wide range of social, commerclal, and institutional responses to technological innovations. The author examine multiple digital platforms and offer a series of case studies from North America, Europe, and Australia. The book delivers fresh insight and analysis from an interdisciplinary perspective, drawing on anthropology, sociology, science and technology studies, human-computer interaction, and media studies. It is key reading for students and scholars in these disciplines, as well as for professional working in bereavement support capacities.

Michael Arnold is Associate Professor and Head of Discipline in the History and Philosophy of Science Programme in the School of Historical and Philosophica Studies at the University of Melbourne, Australia.

Martin Gibbs is Associate Professor in the School of Computing and Information Systems and a member of the Interaction Design Lab (IDL) at the University of Melbourne, Australia.

Tamara Kohn is Associate Professor of Anthropology in the School of Social and Political Sciences and Coordinator of Gender Studies in the Faculty of Arts at the University of Melbourne, Australi

James Meese is Lecturer in the School of Communication at the University of Technology Sydney, Australia.

Bjorn Nansen is Senior Lecturer in Media and Communications at the University of Melbourne, Australia. 